\title{
Evaluación microbiológica de las ambulancias de un Hospital en el departamento de Caldas, 2018.
}

\author{
María Angélica Aristizabal Rivera', Daniela Rincón', Laura Daniela Muñoz', \\ Germán Oved Acevedo Osorio², Adriana Marcela Gómez ${ }^{3}$
}

RESUMEN La atención prehospitalaria es cada vez más reconocida en todo el mundo como una parte fundamental en el sistema de salud, sin embargo, no se le da mucha importancia en cuanto al control de infecciones. Para evitar que las ambulancias sean un foco de trasmisión, se deben implementar protocolos de limpieza y desinfección para disminuir las cargas bacterianas, ya que las ambulancias cuentan con dispositivos médicos que están en contacto con el paciente, y si estos no reciben la limpieza adecuada, se convierten en alto riesgo de infección; además se debe tener en cuenta que no siempre hay la información clara de si el paciente puede tener algún tipo de enfermedad infectocontagiosa, o incluso los profesionales de la salud algunas veces pueden padecer algún tipo de patología o han estado expuestos a pacientes quienes son posibles portadores de microorganismos, y al momento de realizar el traslado de ellos, estos patógenos se pueden propagar, lo cual es un evento adverso que atenta contra la seguridad del paciente y el mismo equipo sanitario, ya que estas infecciones podrían llevar a estancias hospitalarias innecesarias, o incluso a la muerte. Son pocos los estudios que se han realizado sobre estos factores de riesgo que están presentes en el transporte asistencial, por lo tanto, se considera un reto mundial para combatir esta exposición biológica.

PALABRAS Desinfección;

Ambulancias;

Microorganismos:

Protocolos

1 Estudiante, VII Semestre, Instrumentación Quirúrgica, Fundación Universitaria del Área Andina.

2 Asesor, Docente, Fundación Universitaria del Área Andina

3 Asesora Temática, Docente, Fundación Universitaria del Área Andina 


\title{
Microbiological Evaluation of ambulances of a hospital in the department of Caldas, 2018.
}

\begin{abstract}
Everyone as a fundamental part of the health system, however, is not given much importance in terms of infection control. To prevent ambulances from being a source of transmission, cleaning and disinfection protocols should be implemented to reduce bacterial loads, since ambulances have medical devices that are in contact with the patient, and if they do not receive adequate cleaning, they become at high risk of infection; in addition it should be taken into account that there is not always clear information if the patient may have some type of infectious disease, or even health professionals may sometimes suffer from some type of pathology or have been exposed to patients who are possible carriers of microorganisms, and at the time of carrying them out, These pathogens can be spread, which is an adverse event that threatens the safety of the patient and the same health team, since these infections could lead to unnecessary hospital stays, or even death. Few studies have been conducted on these risk factors that are present in healthcare transport, therefore, it is considered a global challenge to combat this biological exposure.
\end{abstract}

Ambulances;

Disinfection;

KEYWORDS Microorganisms:

Protocols 


\section{INTRODUCCIÓN}

La atención prehospitalaria se viene empleando desde hace varios años, solo que antes se utilizaba este traslado en carretas y sin el personal idóneo para ello; con el pasar del tiempo se empezaron a implementar con atención médica. El término de atención prehospitalaria nace en 1940, en esta época los bomberos de Estados Unidos fueron quienes realizaron el primer tratamiento médico de un paciente herido durante su traslado asistencial (1) móvil (hospital, se iniciaron cursos y normas para el personal que realiza el traslado, y con el empleo de nuevas tecnologías este se ha convertido en una parte fundamental para el sistema de salud y para la atención primaria del paciente. Hoy en día se cuenta con el traslado asistencial básico (TAB) y con el traslado asistencial medicalizado (TAM), el cual es estipulado por el Ministerio de Salud y Protección Social, pero son muy pocos los estudios que se realizan referente a los factores de riesgo que pueden estar presentes y los protocolos de desinfección que deben emplearse al momento de realizar la desinfección de la ambulancia y sus insumos médicos.

Las infecciones asociadas a la atención en salud (IAAS), anteriormente conocidas como infecciones nosocomiales u hospitalarias, son las que el paciente adquiere durante su tratamiento o la instancia hospitalaria, y con las cuales el paciente no contaba; estas infecciones también pueden afectar al personal asistencial. Las IAAS son el evento adverso más frecuente, lo cual hace que se prolongue la estancia hospitalaria de un paciente, resistencia a los microorganismos, discapacidades a largo plazo e incluso la muerte, sin contar con que esto también implica una carga financiera en el sistema de salud (2).

La limpieza oportuna de las superficies de la ambulancia, puede reducir significativamente la trasmisión de estos microorganismos, debido a que los vehículos transportan varias personas en un mismo día y se hace un poco complicado invertir el tiempo suficiente para realizar procesos de limpieza y desinfección de los equipos y dispositivos médicos, sin contar que los agentes patógenos también se pueden encontrar en los uniformes y en las manos de los profesionales asistenciales (2).

Es importantes detectar y prevenir estas infecciones, ya que esto genera costos innecesarios y muertes evitables; para ello el Ministerio de Salud crea una acción donde se establece que "una atención limpia es una atención más segura". Esto hace referencia a una buena higienización de manos, seguridad en inyectología, procesos quirúrgicos, atención prehospitalaria, entre otros.

La atención prehospitalaria es cada vez más reconocida en todo el mundo como una parte fundamental en el sistema de salud, sin embargo, no se le da la importancia en cuanto al control de infecciones. Para evitar que este medio sea un foco de trasmisión, se deben implementar protocolos de limpieza y desinfección para disminuir las cargas bacterianas, ya que las ambulancias cuentan con dispositivos médicos que están en contacto con el paciente, y si estos no reciben la limpieza adecuada se convierten en un alto riesgo de infección. 
Según la OMS, cada año cientos de millones de pacientes tratados en centros hospitalarios, ambulatorios o de consulta externa, contraen infecciones nosocomiales. Se considera que, en el mundo, durante el proceso de atención, más de 1,4 millones de pacientes contraen infecciones hospitalarias, siendo el riesgo de infección de 2 a 20 veces mayor en los países en desarrollo que en los países desarrollados. Su verdadera carga mundial es desconocida debido a que no se cuenta con datos estadísticos confiables, pues la mayoría de países carece de programas de vigilancia relacionados con el tema, y aquellos que los tienen, presentan dificultades derivadas de la complejidad y falta de uniformidad de criterios de diagnóstico (3).

Existe una problemática mundial que se ha dejado pasar desapercibida por todo el equipo médico, paramédico y hospitalario en cuanto al control de los agentes patógenos que se pueden encontrar dentro de las ambulancias: el paciente y el mismo personal sanitario que presta la atención, ya sea porque no se realiza un adecuado lavado de manos, no se encuentra bien protocolizado la desinfección de las ambulancias, no se utilizan los antisépticos apropiados, o simplemente porque son jornadas de trabajo muy extensas, donde el personal que labora no se cambia la ropa y esta puede estar impregnada de agentes patógenos dentro de los cuales se encuentran Staphylococcus aureus, estafilocos coagulasa negativa y otros cocos Gram-positivos (4). Estos agentes patógenos causan infecciones en la piel, neumonía, endocarditis, osteomielitis, gastroenteritis, su gravedad varía dependiendo el tipo de paciente, y si existen factores de riesgo.

La Política de Seguridad del Paciente en Colombia, está liderada por el Sistema Obligatorio de Garantía de Calidad de la Atención en Salud (SOGC), donde se busca prevenir, reducir, y de ser posible eliminar los eventos adversos para que las instituciones puedan ser más seguras y competentes. La seguridad del paciente debe ser una prioridad y estos eventos adversos son los que nos advierten que la atención que se está brindado no es cien por ciento segura (5).

Como el traslado asistencial de pacientes también se considera un foco de infección para los enfermos y los tripulantes de la misma, ya que un paciente con alguna enfermedad infectocontagiosa puede toser, estornudar, orinar, o eliminar microorganismos de alguna otra manera hacia el interior de la ambulancia, y estos microorganismos pueden utilizar superficies sólidas para crear sus colonias, las cuales consiguen ser inhaladas, ingeridas, tocadas por algún otro pasajero de la ambulancia o por el mismo personal de asistencia médica (6)the ambulance remains vulnerable to bacterial contamination from biological secretions. Additionally, the nature of emergency medical services creates pressures on prehospital care providers. OBJECTIVE: We hypothesized that a discrepancy exists between the expectation of disinfection of reusable equipment in emergency medical services (EMS. Existen protocolos para realizar el proceso de limpieza y desinfección de los elementos que están dentro del transporte y con los cuales se tiene contacto directo e indirecto, pero vemos que muchas instituciones no los tienen o no los hacen cumplir, lo que facilita que se creen estas colonias de microorganismos que pueden ser letales, y contribuir a que un paciente que se encuentra aparentemente sano, adquiera una infección. 
Nuestro estudio se basó en tomar 4 ambulancias del departamento de Caldas donde se realizó la toma de varias muestras de puntos estratégicos para verificar si el proceso de limpieza y desinfección se realiza de manera efectiva, o si por el contrario se encuentran microorganismos presentes.

\section{METODOLOGÍA}

Tipo de Estudio: estudio Observacional, Descriptivo, Transversal, Prospectivo.

Población y muestra: la población está conformada por $\mathrm{N}=4$ ambulancias de un hospital del departamento de Caldas, mediante un muestreo a conveniencias de las instituciones de salud que desearon y aceptaron participar en el estudio.

Unidad de Análisis: la unidad de análisis es cada una de las ambulancias del hospital del departamento de Caldas.

Recolección de la información: se efectuó una recolección de muestras microbiológicas de los vehículos sanitarios, mediante el método de hisopado, el cual consiste en frotar con un hisopo estéril una superficie, y se realizó siembra de superficie en agar sangre.

Análisis de información: los frotis se tomaron con las ambulancias listas para prestar servicio.

Las muestras fueron tomadas con la técnica de frotis de superficie; para ello se usó agua peptonada y aplicadores estériles; posteriormente se sembraron en agar sangre en superficie e incubadas a $37^{\circ} \mathrm{C}$ durante 48 horas, para ser analizados en equipo automatizado.

Se realizó control de calidad a cada medio utilizado

Componente Bioético: según la Resolución 008430 de 1993 y el Comité de Investigaciones del programa de Instrumentación Quirúrgica, se considera un estudio de riesgo mínimo.

\section{RESULTADOS}

Indican la presencia de microorganismos que hacen parte de la microbiota, esto es un indicador de contaminación por fluidos orgánicos, y aunque no se tienen antecedentes y estándares para la presencia o ausencia de los mismos en ambulancias, se sugiere realizar un estudio más amplio, realizando un comparativo entre varias instituciones y con protocolos que evalúen los procedimientos de limpieza y desinfección, ya que como se muestra a continuación en la siguiente tabla, los sitios más críticos son las manijas de la puerta, la gaveta de medicamentos y las camillas; estos puntos en los 4 vehículos arrojaron presencia de microrganismos, siendo el regulador de oxígeno y el dispensador de gel los puntos menos críticos. 
Tabla 1.

Resultados microbiológicos de análisis superficie ambulancias departamento de Caldas.

\begin{tabular}{|c|c|c|c|}
\hline PLACA & $\begin{array}{l}\text { LUGAR DE TOMA DE } \\
\text { MUESTRA }\end{array}$ & RESULTADO 1 & RESULTADO 2 \\
\hline \multirow[t]{5}{*}{ Vehículo 1} & Regulador de Oxígeno 1 & $\begin{array}{l}\text { Staphylococcus } \\
\text { epidermidis }\end{array}$ & Micrococcus luteus \\
\hline & Manija Puerta 4 & $\begin{array}{l}\text { Staphylococcus } \\
\text { epidermidis }\end{array}$ & Micrococcus luteus \\
\hline & Dispensador de Gel 1 & NEGATIVO & NEGATIVO \\
\hline & Gaveta Medicamentos 4 & Bacillus gram positivos & NEGATIVO \\
\hline & Camilla 4 & $\begin{array}{l}\text { Staphylococcus } \\
\text { epidermidis }\end{array}$ & $\begin{array}{l}\text { Staphylococcus } \\
\text { vitulinus }\end{array}$ \\
\hline \multirow[t]{5}{*}{ Vehículo 2} & Regulador de Oxígeno & NEGATIVO & NEGATIVO \\
\hline & Manija Puerta & $\begin{array}{l}\text { Staphylococcus } \\
\text { epidermidis }\end{array}$ & Micrococcus luteus \\
\hline & Dispensador de Gel & Kocuria kristinie & NEGATIVO \\
\hline & Gaveta Medicamentos & Kocuria kristinie & $\begin{array}{l}\text { Staphylococcus } \\
\text { epidermidis }\end{array}$ \\
\hline & Camilla & $\begin{array}{l}\text { Staphylococcus } \\
\text { epidermidis }\end{array}$ & Micrococcus luteus \\
\hline \multirow[t]{5}{*}{ Vehículo 3} & Regulador de Oxígeno & NEGATIVO & NEGATIVO \\
\hline & Manija Puerta & $\begin{array}{l}\text { Staphylococcus cohnii } \\
\text { urealyticum }\end{array}$ & $\begin{array}{l}\text { Staphylococcus } \\
\text { epidermidis }\end{array}$ \\
\hline & Dispensador de Gel & NEGATIVO & NEGATIVO \\
\hline & Gaveta Medicamentos & Micrococcus luteus & NEGATIVO \\
\hline & Camilla & Staphylococcus cohnii & Micrococcus luteus \\
\hline \multirow[t]{5}{*}{ Vehículo 4} & Regulador de Oxígeno & NEGATIVO & NEGATIVO \\
\hline & Manija Puerta & $\begin{array}{l}\text { Staphylococcus } \\
\text { epidermidis }\end{array}$ & NEGATIVO \\
\hline & Dispensador de Gel & NEGATIVO & NEGATIVO \\
\hline & Gaveta Medicamentos & $\begin{array}{l}\text { Staphylococcus } \\
\text { epidermidis }\end{array}$ & NEGATIVO \\
\hline & Camilla & $\begin{array}{l}\text { Staphylococcus } \\
\text { epidermidis }\end{array}$ & Micrococcus luteus \\
\hline
\end{tabular}

Fuente: Propia 
1. Mart EC, Ter BB, Torres AA. La historia de la ambulancia. Rev la Asoc Mex Med Crit y teraia intensiva. 2006;3:103-4.

2. Vikke HS, Giebner M, Kolmos HJ. Prehospital infection control and prevention in Denmark: A cross-sectional study on guideline adherence and microbial contamination of surfaces. Scand J Trauma Resusc Emerg Med. 2018;26(1):17 .

3. Reyes-del Valle J, de la Fuente C, Turner MA, Springfeld C, Apte-Sengupta $\mathrm{S}$, Frenzke ME, et al. Detectar, prevenir y reducir infecciones asociadas con la atencion en salud [Internet]. Vol. 86, Journal of Virology. 2012. Available from: http://jvi.asm.org/cgi/doi/10.1128/JVI.01776-12

4. Lozano JC. Transportando infecciones nosocomiales. Vol. XXVI, Transportando infecciones nosocomiales. 2013.

5. Ministerio de Salud y Protección Social. Seguridad del paciente y la atención segura. 2014

6. Alves DW, Bissell RA. Bacterial pathogens in ambulances: Results of unannounced sample collection. Prehospital Emerg Care. 2008;12(2):218-24.

7. Fariña N, Carpinelli L, Samudio M, Guillén R, Laspina F, Sanabria R, et al. Staphylococcus coagulasa-negativa clínicamente significativos: Especies más frecuentes y factores de virulencia. Rev Chil infectología [Internet]. 2013;30(5):480-8. Available from: http://www.scielo.cl/scielo.php?script=sci arttext\&pid=S0716-10182013000500003\&lng=en\&nrm=iso\&tlng=en

8. Slater K, Cooke M, Whitby M, Fullerton F, Douglas J, Hay J, et al. Microorganisms present on peripheral intravenous needleless connectors in the clinical environment. Am J Infect Control [Internet]. 2017;45(8):932-4. Available from: http://dx.doi.org/10.1016/j.ajic.2017.02.008

9. PEDRO MARTÍNEZ SM. Posible aislamiento clínico de Staphylococcus cohnii resistente a vancomicina. Asoc Colomb INFECTOLOGÍA. 2006;10(3):175-7.

10. Usó J, Gil M, Gomila B, Tirado MD. Endocarditis por Micrococcus luteus. Enferm Infecc Microbiol Clin. 2003;21(2):116-7. 